Document downloaded from:

http://hdl.handle.net/10251/66306

This paper must be cited as:

Galindo, J.; Serrano Cruz, JR.; Dolz Ruiz, V.; López Hidalgo, MA.; Bouffaud, F. (2013). Behavior of an IC Engine Turbocharger in Critical Conditions of Lubrication. SAE International Journal of Engines. 6(2):1-9. doi:10.4271/2013-01-0921.

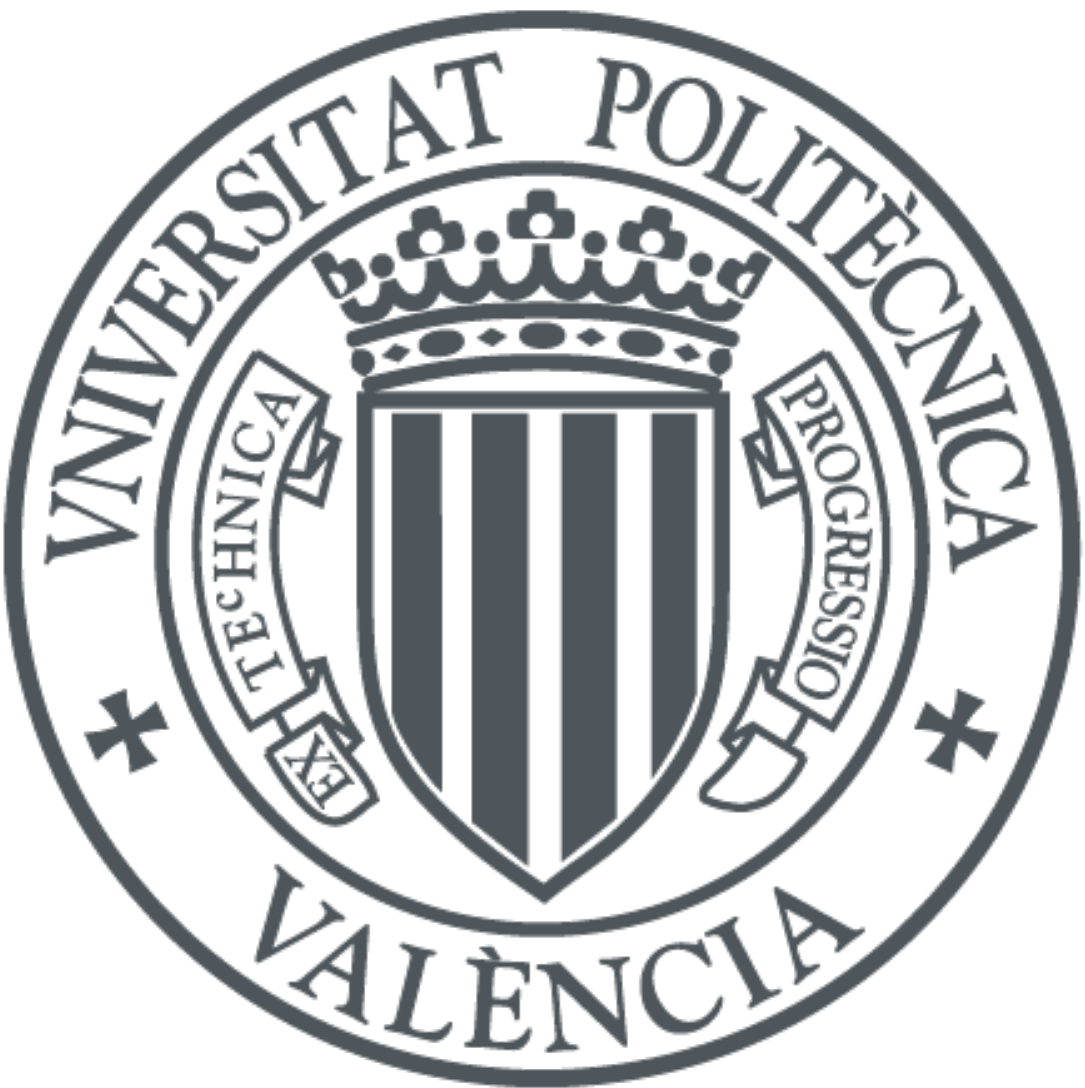

The final publication is available at

http://dx.doi.org/10.4271/2013-01-0921

Copyright SAE International

Additional Information 


\title{
Behavior of an IC engine turbocharger in critical conditions of lubrication
}

\author{
J. Galindo, J.R. Serrano, V. Dolz, M. A. López \\ CMT-Motores Térmicos. Universitat Politècnica de València, Spain \\ F. Bouffaud \\ RSA-Renault SA, France
}

\section{ABSTRACT}

Problems in the turbocharger lubrication system can cause serious deterioration in their overall performance and even their complete destruction. The paper describes several tests with different critical lubrication conditions, in order to determine the thresholds at which the operation may be appropriate. In an IC engine, these problems can be produced mainly by several factors: the decreasing in the supply pressure of the oil, a delay in the lubrication oil pressure and an intermittent lubrication interruption. A turbocharger test bench and an IC engine test bench has been used to test the turbocharger, in order to reproduce the conditions and cycles similar to the operation of the turbocharger in an IC engine (pressures, temperatures, mass flows, accelerations, etc..). Thermodynamic variables and mechanic variables measured in the tests help to identify some of the operating limits of lubrication in critical conditions. In addition, optical techniques have been combined with accelerometer measurements, in order to detect modifications in the movement of the turbocharger shaft. The main conclusions obtained from these tests are that accelerations from low rotational speed to $100 \mathrm{krpm}$, without lubrication oil in the bearing system, don't cause significant problems in the turbocharger, for 20 sec. However, the accelerations to $150 \mathrm{krpm}$ can cause critical problems depending on the lubrication delay and the bearing configuration. Finally, higher acceleration rates to $200 \mathrm{krpm}$, without lubrication, cause the turbocharger destruction in a few seconds. By other hand, a low oil inlet pressure given by an oil column, of about $1 \mathrm{~m}$ in height, allows to the turbo survive during accelerations from low rotational speed to $150 \mathrm{krpm}$.

\section{INTRODUCTION}

Nowadays turbochargers are one of the most efficient ways to improve the performance of internal combustion engines [1] and comply with the downsizing trend for energy saving, but the turbocharger is subject to critical operating conditions such as high rotational speeds or surge conditions. Therefore, it is essential to know the limits at which it can work properly. That's why in recent times it has been growing the interest in studying the turbocharger behavior over different extreme operating conditions which can even produce the total turbocharger failure. One of the most delicate parts for the turbocharger performance is its lubrication system. For this reason, this paper exposes several experiments to provide more understanding of the failures that can occur on related systems.

Most models and experimental studies [2] [3] have been carried out in non-critical operation conditions in the turbocharger; this allows a characterization as reliable as possible. However, the experiments proposed in this paper are aimed to provide relevant information in critical operation conditions. Several areas of study are benefiting from these studies: The control strategies can extend the areas in which commonly the turbocharger is operating [4] [5], thus raising the overall system performance. The design of the lubrication circuit can draw on this knowledge to increase the protection of the turbocharger components exposed to these critical conditions [6] [7]. The new engine work strategies as the "start-stop engines" [8], can induce new problems related with the lubrication system as the delay of lubrications when the engine starts or the sudden oil cut when the engine stops.

In order to better understand the turbocharger behavior, it is necessary to use a measurement technique that allows estimating the turbocharger shaft motion. This shaft motion allows to know deeper the overall working conditions of the turbocharger and for this reason several techniques have been considered [9] [10] [11]. However, having to perform critical tests can result in the total destruction of the turbocharger and the sensors. So, a non-invasive optical technique has been considered, in order to reproduce the original working conditions of the turbocharger and to avoid the sensors destruction. In this paper, the optical technique based in a high

Page 1 of 9 
performance camera and described in [12] has been considered.

\section{METHODOLOGY}

The tests were performed in different test benches where the main thermodynamic variables were measured (pressure, temperature and mass flow rate). Furthermore, the optical technique [12] is used to estimate the motion of the shaft.

An image recording methodology and a process algorithm defined in [12] have been applied in order to estimate the shaft motion. This processing consists on differentiating specific zones of the shaft tip image in the compressor side, in order to obtain the relative coordinates of this shaft tip. Two reference points have been configured on the compressor side, which help to calculate the relative position of the shaft tip, avoiding the errors due to structural vibrations.

The first step to measure the shaft motion is to estimate the maximum eccentricity of the shaft. The maximum eccentricity is the mechanical limit in which the shaft could work in normal way. This limit is due to the different components of the turbo when they are not worn. Then, if the shaft overcomes this limit, several components of the turbocharger could have been damaged. The maximum eccentricity of the turbochargers has been determined and it has been compared with shaft motion in each test.

Two different tests have been considered to study the critical lubrication conditions of a turbocharger. The first is the resistance test; it consists in conducting five accelerationdeceleration cycles in several phases, in which the inlet oil pressure decreases step by step. The second is the lubrication delay test; it consists on delay the lubrication of the turbocharger up to several seconds after its acceleration. Finally, the root causes of the lost of boost pressure after a critical turbocharger failure occurs (for example, after a lack of lubrication or during intermittent lubrication [12]) have been studied.

\section{Lubrication delay tests}

In these tests, the turbocharger is accelerated and decelerated from zero level up to $50000 \mathrm{rpm}, 100000 \mathrm{rpm}, 150000 \mathrm{rpm}$ and $200000 \mathrm{rpm}$. These acceleration-deceleration cycles are generally repeated 30 times. When turbocharger accelerates the lubrication is reconnected with different delays (8, 12, 16 or 20 seconds delay), as shown Figure 1.

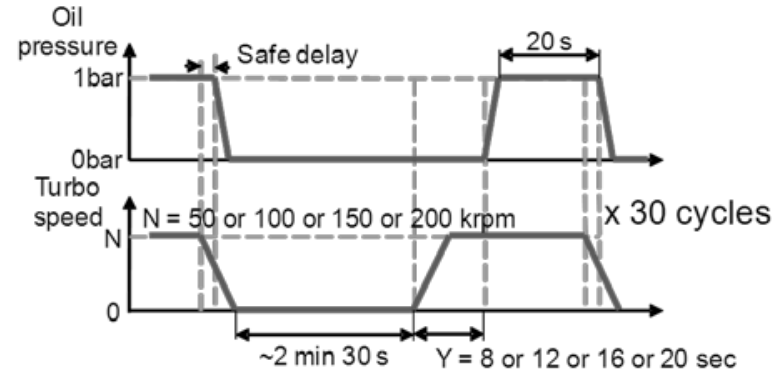

Figure 1 Lubrication delay test

\section{Resistance tests}

In these tests, the turbocharger is accelerated and decelerated from $30000 \mathrm{rpm}$ to $150000 \mathrm{rpm}$. These accelerationdeceleration cycles have been repeated 5 times. After, turbocharger inlet oil pressure is decreased as shown Figure 2, until the "oil tank phase" with a minimum oil pressure, when an oil tank feeds the lubrication circuit and the inlet oil pressure is determined by an oil column of about $1 \mathrm{~m}$ in height.

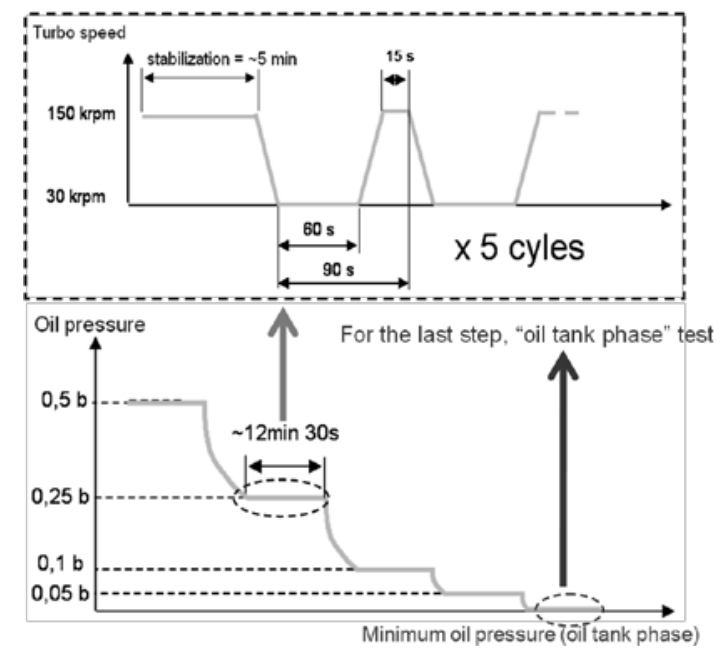

Figure 2 Resistance test

\section{Damaged Compressor wheel test}

When the turbocharger destruction is produced, for example after intermittent lubrication or a period with a lack of lubrication, two usually main failures are produced; the blades tip deformation of the wheels and the wear of the bearings. In order to clarify whether the boost pressure of the turbocompressor is lost by critical failure caused by deformation of the blades or by wear of the bearings, an additional test was conducted. This test consisted in measuring different operative points in steady conditions, using a new turbocharger and comparing these results with the same turbocharger but 
replacing the compressor wheel by a compressor wheel with the blades damaged during a lack of lubrication test [12]. The objective is to observe the differences with this damaged wheel. These two configurations of the turbocharger were tested at different steady conditions with two different resistance curves.

\section{TEST BENCH LAYOUT}

The tests of this study have been made in a turbo test bench that uses an IC engine to generate exhaust gases which provide energy to the turbine [3]. Figure 3 shows a sketch of this test bench.

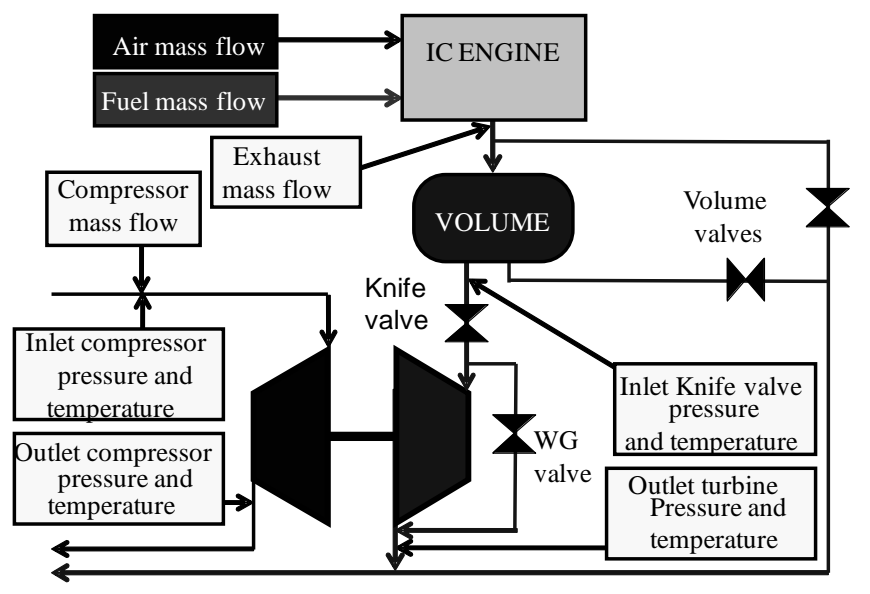

Figure 3 Sketches of air and exhaust gasses circuits

In Figure 3, the white squares show where are located the pressure, temperature and mass flow sensors. The volume valves are slow control valves, which serve to control the pressure before the turbine. By contrast, the knife gate valve is a valve used to test rapid accelerations and rapid decelerations of turbochargers.

The oil circuit has been modified to perform the required tests. Figure 4 shows a schematic of the turbocharger lubrication system.

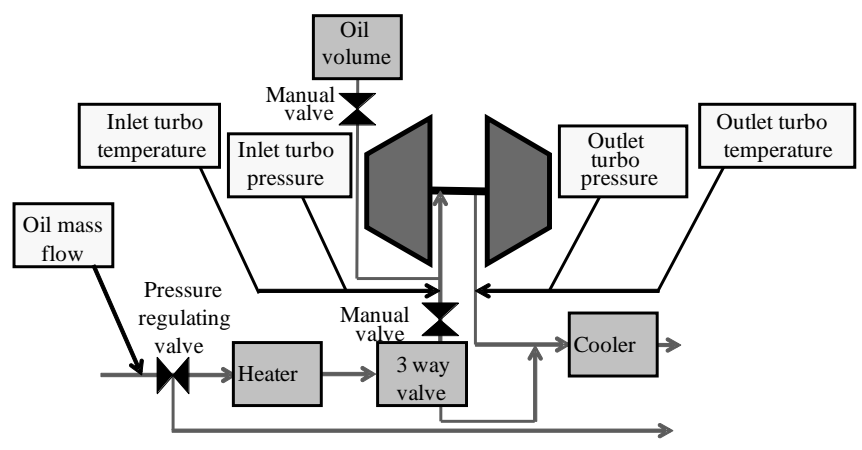

Figure 4 Lubrication circuit sketch

As in the previous figure, the white squares show where there are located the sensors of pressure, temperature and mass flow. The heater and cooler are used to control the temperature of oil in the turbocharger lubrication circuit. The three-way valve bypasses turbocharger to simulate lubrication system failures. In addition, the oil pressure to the turbo inlet can be controlled with a pressure regulating valve. It's possible feed the lubrication circuit of the turbo using an oil volume (during the "oil tank phase" of the resistance tests) that can be connected to the turbocharger by mean a manual valve, which allows the operation of the turbo with small oil pressures.

A camera is placed in front of the turbocharger on the compressor side, positioning it as coaxial as possible to the turbocharger shaft and focused to the shaft tip, in order to film and measure the turbocharger shaft motion [12].

\section{DISCUSSION OF THE RESULTS}

Several experiments were conducted for each of the proposed tests, in order to check the repeatability. These tests were done with two types of turbochargers: the first type has full floating bearing and the second type has semi floating bearing. However, to avoid an excessive length, this paper only discusses the most significant test results.

\section{Lubrication delay tests}

In these tests was detected that the critical conditions which can produce the turbocharger destruction are accelerations up to $200 \mathrm{krpm}$. The test presented in this paper is a test with this type of acceleration and a time delay of 20 seconds for lubrication oil. The accelerations up to $150 \mathrm{krpm}$ didn't present any strange behavior, despite similar lubrication delays where tested. These accelerations were very sharp accelerations done with the knife gate valve.

The turbo shaft was blocked in the first cycle of the test, 15 seconds after the acceleration without lubrication. Figure 5 shows pressures, temperatures and compressor mass flow measurements during this acceleration. Note that the P_IKGV is the pressure upstream the knife gate valve. Figure 3 shows the setup of the installation and the place where this pressure is measured.

Page 3 of 9 


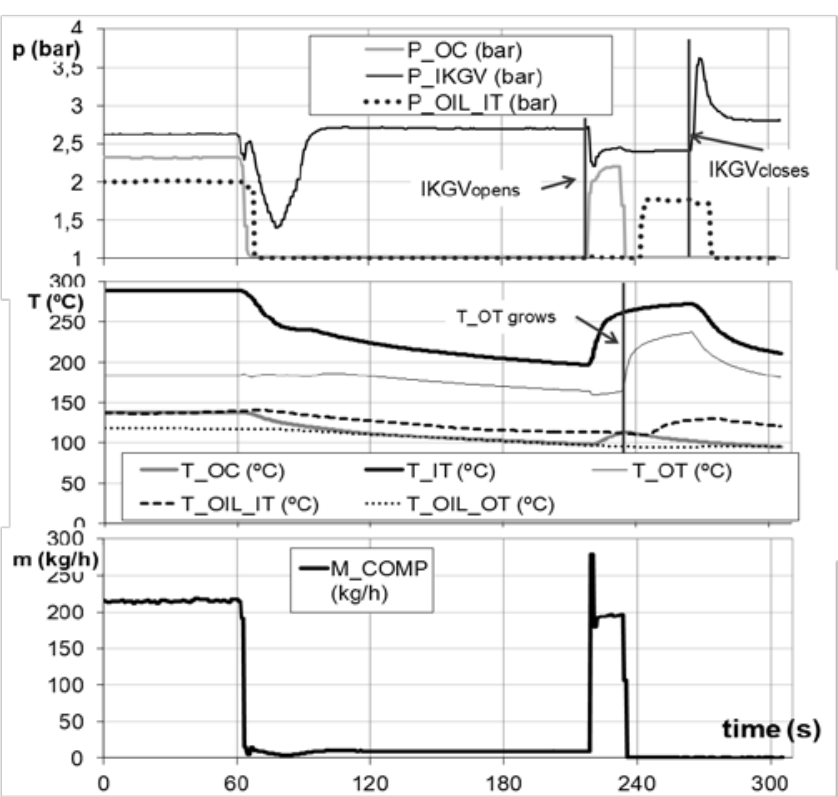

Figure 5 Lubrication delay test, pressures, temperatures and compressor mass flow measurements

The turbo shaft was completely blocked in the second 235. At this point, the compressor stops working and it is possible to see a temperature increment at the turbine outlet, because the shaft is stopped. Figure 6 shows the shaft motion measured with the camera during this first cycle.

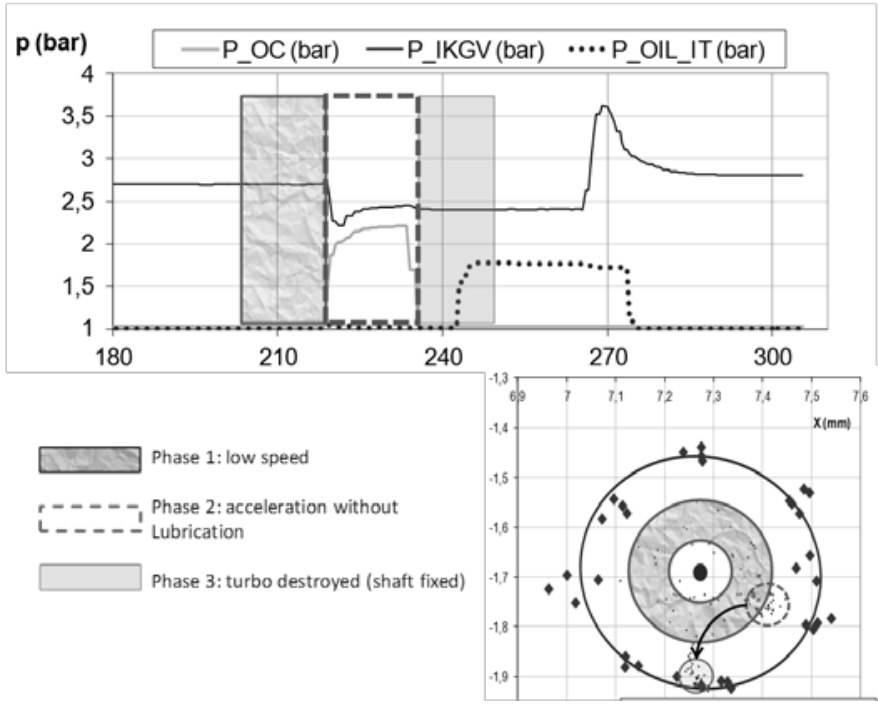

Figure 6 lubrication delay test, shaft motion

This shaft motion can be studied in three phases:

Phase 1. The turbocharger rotates at very low speed (about 5000rpm) and the shaft moves through the area of the figure marked in centre circle of Figure 6.

Phase 2. The turbo is accelerated without lubrication and the shaft moves concentrated in the area of the figure marked in right circle of Figure 6.

Page 4 of 9
Phase 3. The turbo shaft is fixed and it moves following down arrow way and is concentrated in the area of the figure marked in down circle of Figure 6.

In order to represent the shaft tip motion in 2D graphs during this experiment, four parameters have been defined and calculated to be analyzed. Figure 7 shows an sketch with these four parameters; The distance to centre (d_c) shows an evolution during the test of the relative distance between the shaft tip and the centre of the maximum eccentricity, the distance to maximum eccentricity (d_me) shows the minimum distance from the shaft tip to the maximum eccentricity, the angle of maximum eccentricity ( $\alpha \mathrm{me}$ ) shows an angle that is counting from the positive $\mathrm{X}$ axis in clockwise direction and the displacement (disp) shows the displacement between two consecutive positions of the shaft tip along the experiment.

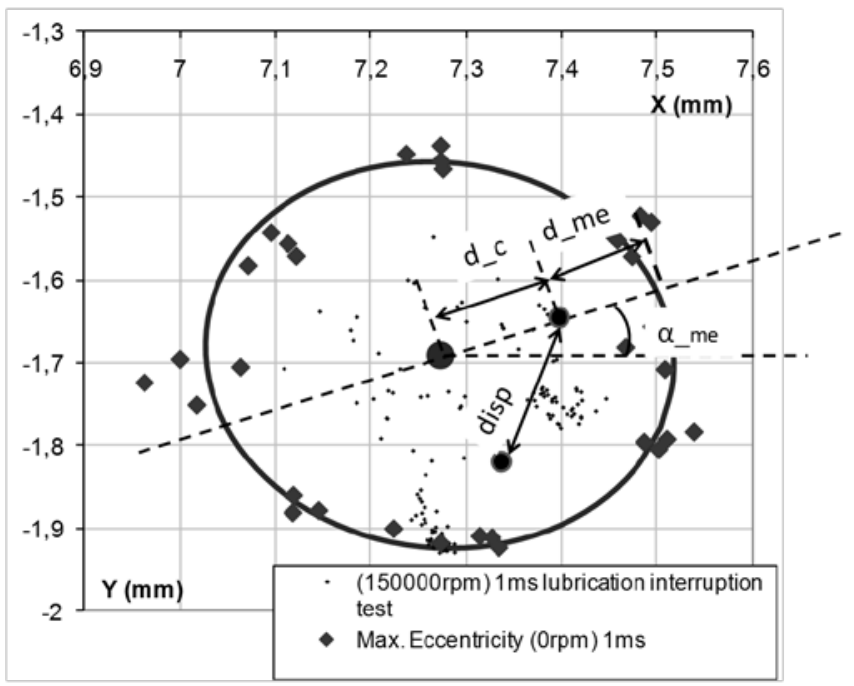

Figure 7 Parameters of shaft motion

Figure 8 shows these parameters versus time during the test. Figure 8.a. shows the distance to center (d_c). This distance increases slightly when the turbocharger increases its speed without oil (between 220s and 240s) and it arrives to the maximum eccentricity $(0.25 \mathrm{~mm}$ approx.) when the shaft is blocked at 240s. Figure 8.b. shows the distance to maximum eccentricity (d_me) and the behavior is the opposite side of the previous parameter. Figure 8.c. shows the angle, which increases to $340^{\circ}$ when the turbocharger accelerates without oil up to reaching 2.2 bar of boost pressure, due to the concentrated movement of the shaft and it decreases to $270^{\circ}$ when the shaft is blocked. Finally, Figure 8.d. shows the displacement (disp). When the shaft is spinning at low speeds, the displacement is the biggest, due to the scattered movement of the shaft at these low regimes. After, when the turbocharger accelerates, the shaft motion is concentrated and the displacement is reduced. Finally, when the shaft is blocked, the displacement trends to zero. 


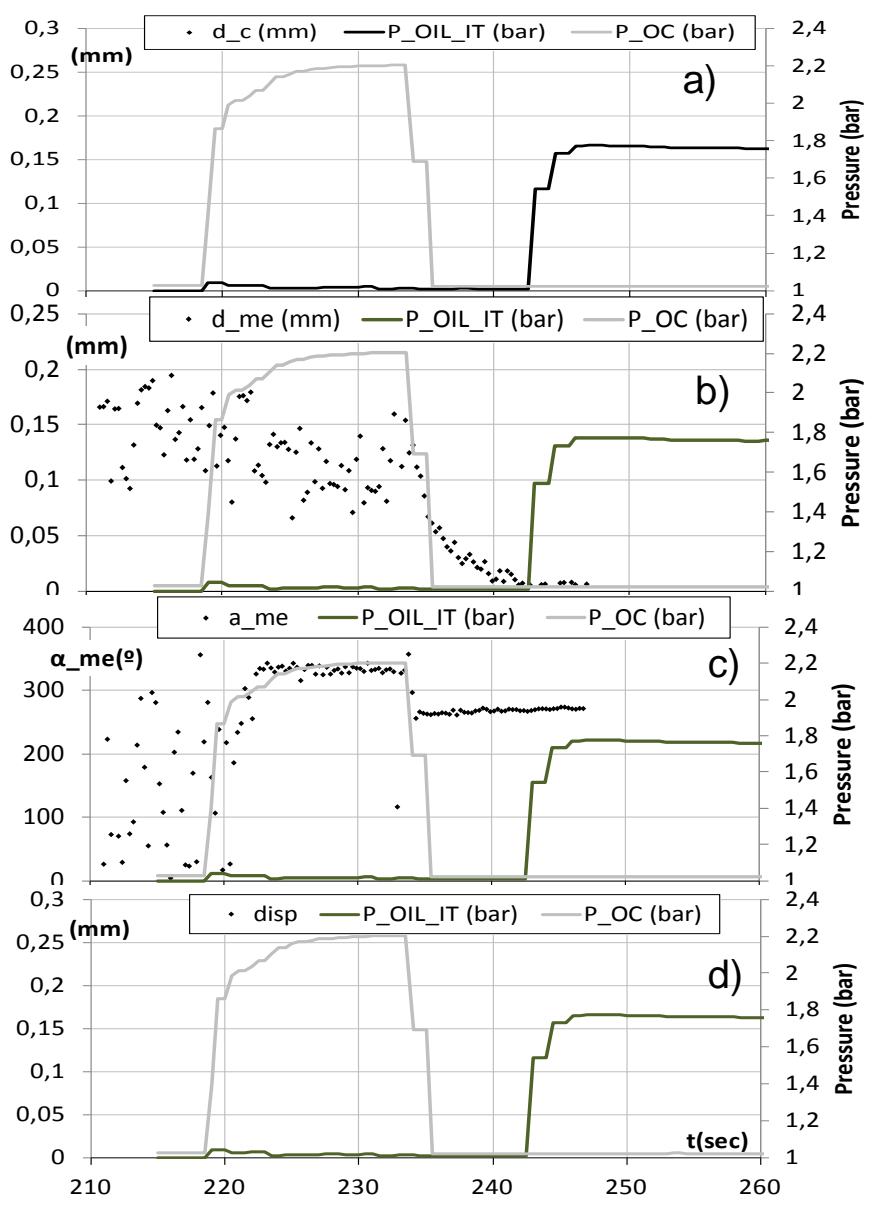

Figure 8 Relative position of the shaft

When turbocharger was disassembled, it presented kicks and scratches in turbine and compressor wheels and housing, as can be observed in Figure 9. These hits produced the bending of the blades showed in Figure 9. In this test, only one blade in compressor wheel and one blade in turbine wheel presented big deformations, they can be observed in the figure. Additionally, the shaft had material addition from radial and axial bearings due to the contact shaft-bearing. Moreover, the compressor nut was completely unscrewed (the nut could be extracted by hand when the compressor wheel was disassembled), due to the abrupt deceleration of the shaft when it was blocked. Probably, a small shaft imbalance produced that the closest blades to this imbalance zone hit the housing during extreme operating conditions of the test (high speed and without lubrication). This behavior causes wear of the bearings and finally, the shaft is blocked, producing an abrupt deceleration and as a consequence the nut unscrewed.
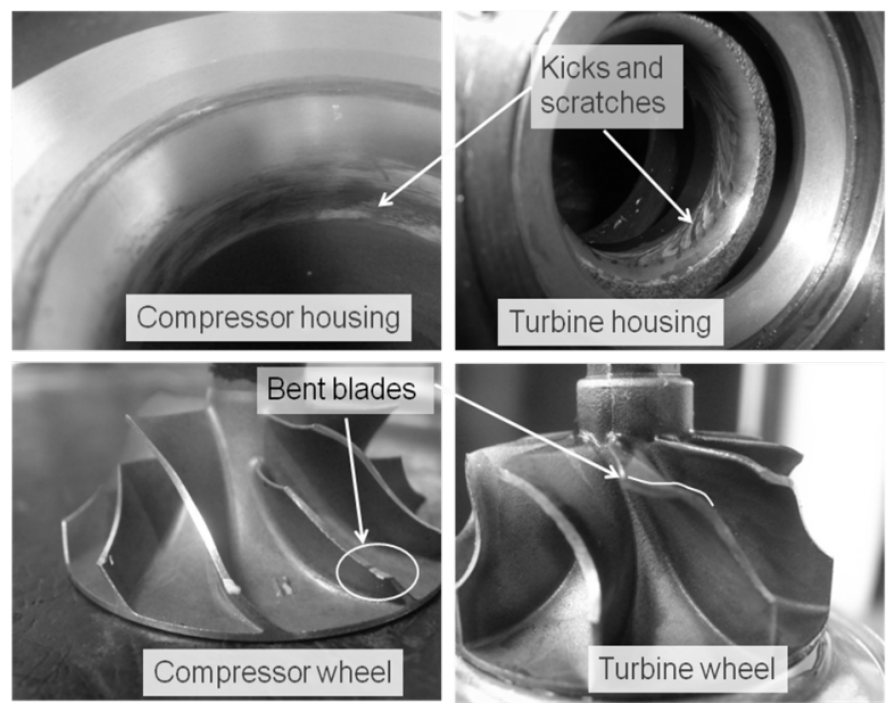

Figure 9 Compressor and turbine wheels after the test

\section{Resistance tests}

These tests have not presented notable incidents until the final phase (oil tank phase). Figure 10 shows pressures, temperatures and mass flow measurements for this last part (oil tank phase).

Figure 10 shows the increasing and decreasing in pressure and mass flow, when turbocharger is accelerated and decelerated. Only at the end of the test, between the second 780 and the second 840 approximately, can be seen that there is an apparent "turbocharger failure", because the compressor stops boosting and the turbine works with poor performance (the gas temperature at turbine outlet increases). This is due to an erratic shaft motion that lasts a few seconds and returns to normal motion spontaneously. The turbo never stops during this phase as recorded films showed. 


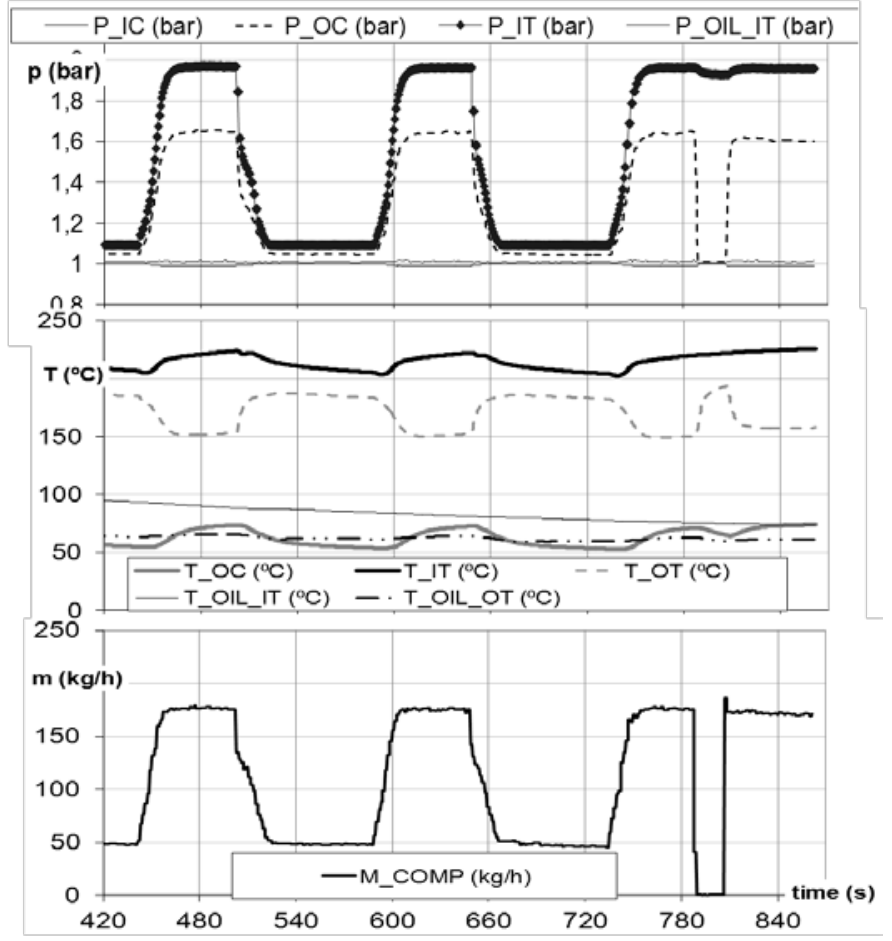

Figure 10 Resistance test, pressures, temperatures and compressor mass flow measurements

In the accelerometer signal, Figure 11, it is possible to observe that the intensity of vibration in this conflictive phase of the test has increased significantly at specific frequencies. The bottom graph of Figure 11 shows the frequency spectrum of the accelerometer signal during this turbocharger failure. Figure 11 shows the main frequencies of the spectrum are multiples of $900 \mathrm{~Hz}$ and these multiples are attenuated above $11700 \mathrm{~Hz}$ Probably, the erratic movement of the shaft during this period is due to kicks of part of the wheel against the turbocharger stator, which are occurring at that frequency of 900-Hz.
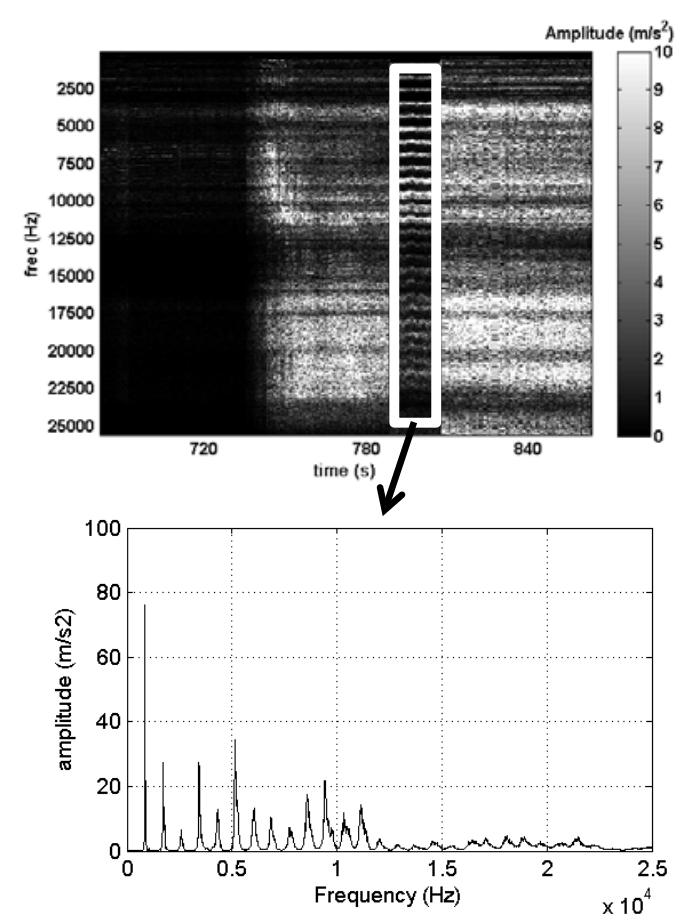

Figure 11 Resistance test, accelerometer signal

Figure 12 shows the operating points on turbocharger compressor map, during this oil tank phase. The central arrows indicate the 5 paths of turbocharger speed decrease and increase, during the 5 cycles. The path followed to increase and decrease turbocharger speed is very similar. The external arrows indicate turbocharger behavior, when it suffered the failure between 780 and 840 seconds in Figure 10. It's possible to observe that when the turbocharger speed decreases, it takes place close to surge zone (first air mass flow decreases and then compression ratio), but when speed increase, it takes place close to choke zone (first increases air mass flow and then compression ratio).

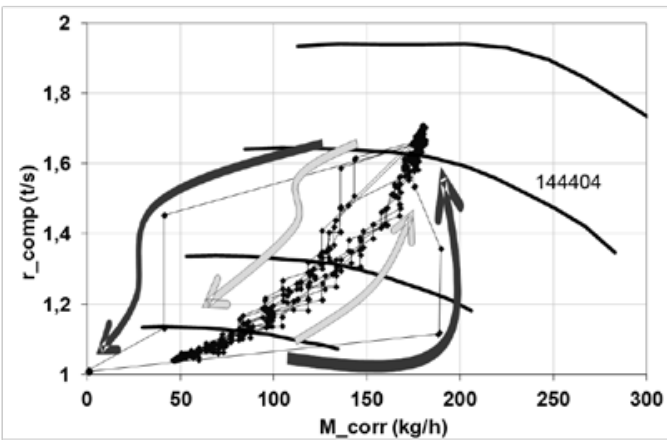

Figure 12 Resistance test, compressor map

\section{Damaged compressor wheel test}

In order to compare the performance of a turbo with a new compressor wheel against its performance with a damaged compressor wheel, the new compressor impeller was replaced 
by the damaged impeller of Figure 13. The turbo was tested at different steady conditions with two different resistance curves. These points are represented in the compressor map in the Figure 14. The points tests were performed with the same thermodynamic parameters in the turbine (same pressure, temperature and turbine mass flow), in order to compare the performance of the two configurations (new impeller and damaged impeller). Figure 14 shows the performance loss of the turbocharger due to the damaged compressor wheel, for each of the two resistance curves. This test demonstrates that the destruction of the turbo (complete loss of the compression ratio) is not only due to the damage of the compressor wheel. It seems that the compressor wheel with damaged blades affects to the aerodynamical behavior of the air through the compressor wheel. Consequently, it decreases the compressor efficiency, but it not produces the complete compressor destruction (when compressor can't compress the air). Other words, defects in the shaft and bearings are the main causes of this complete loss of compression ratio.

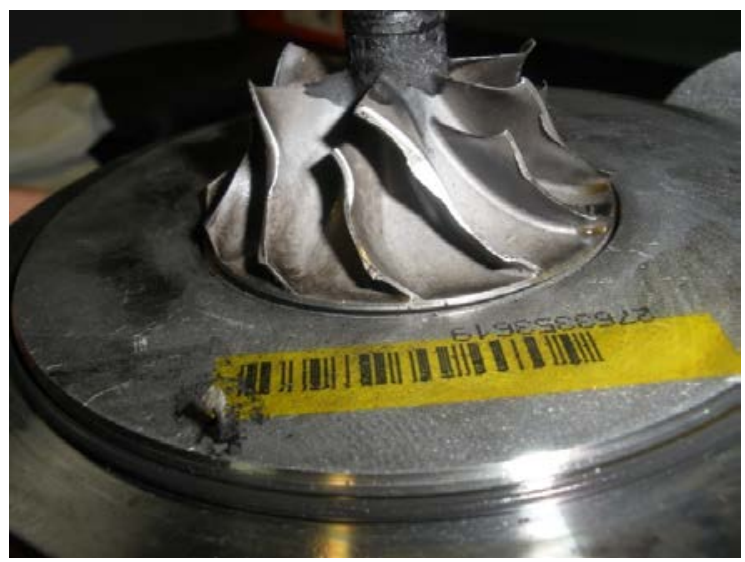

Figure 13 Damaged impeller

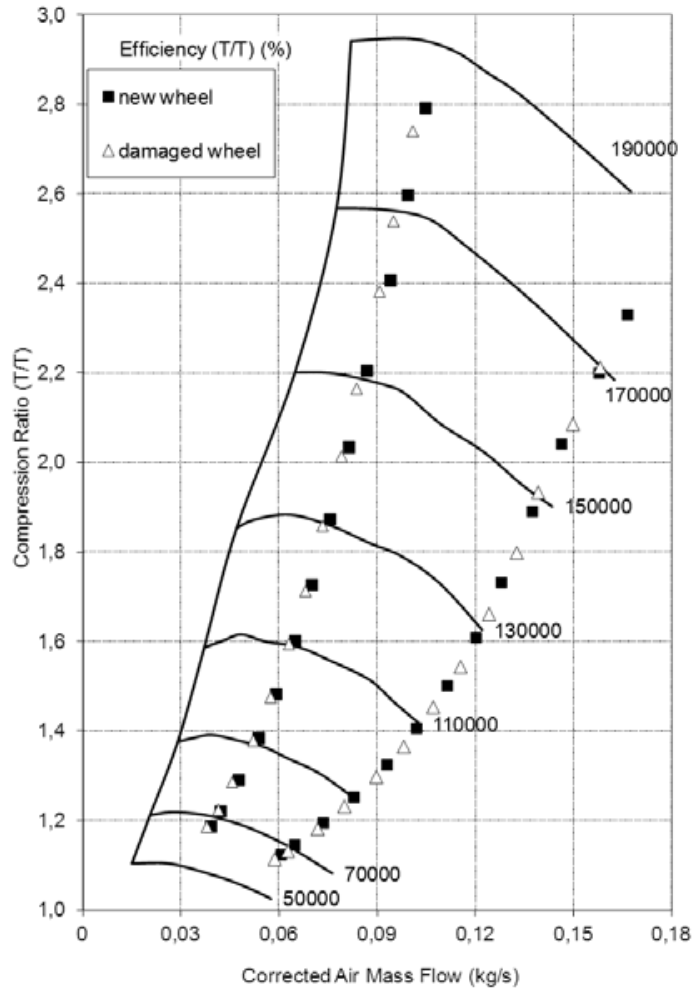

Figure 14. Damaged wheel effects on the compressor map

The following figures Figure 15 and Figure 16 shows changes in the corrected turbocharger speed, compression ratio, corrected mass flow, compression efficiency and turbocharger efficiency between the new turbo and turbo with the damaged wheel, in the two resistance curves. These figures show that the most significant effect of the damaged compressor wheel is a substantial loss of turbocharger efficiency defined as (1).

$$
\eta_{T G}=\frac{\dot{W}_{c o m p}^{i s e n t}}{\dot{W}_{t u r b}^{i s e n t}}=\frac{\dot{m}_{\text {comp }} T_{10} C_{p i}\left(\left(\Pi_{c}\right)^{\frac{\gamma-1}{\gamma}}-1\right)}{\dot{m}_{t u r b} T_{30} C_{p e}\left(1-\left(\frac{1}{\Pi_{e}}\right)^{\frac{\gamma-1}{\gamma}}\right)}
$$

Where $\eta_{T G}$ is the efficiency of the turbocharger, $\dot{W}_{\text {comp }}^{\text {isent }}$ and $\dot{W}_{\text {turb }}^{\text {isent }}$ are the isentropic power of compressor and turbine respectively, $\dot{m}_{\text {comp }}$ and $\dot{m}_{\text {turb }}$ are the air mass flow of compressor and turbine, $T_{10}$ and $T_{30}$ are the total temperatures at compressor inlet and turbine inlet, $C_{p i}$ and $C_{p e}$ are specific heat at the intake and the exhaust lines, $\Pi_{c}$ and $\Pi_{e}$ are the compression ratio and expansion ratio and finally, $\gamma$ is the specific heats ratio. 


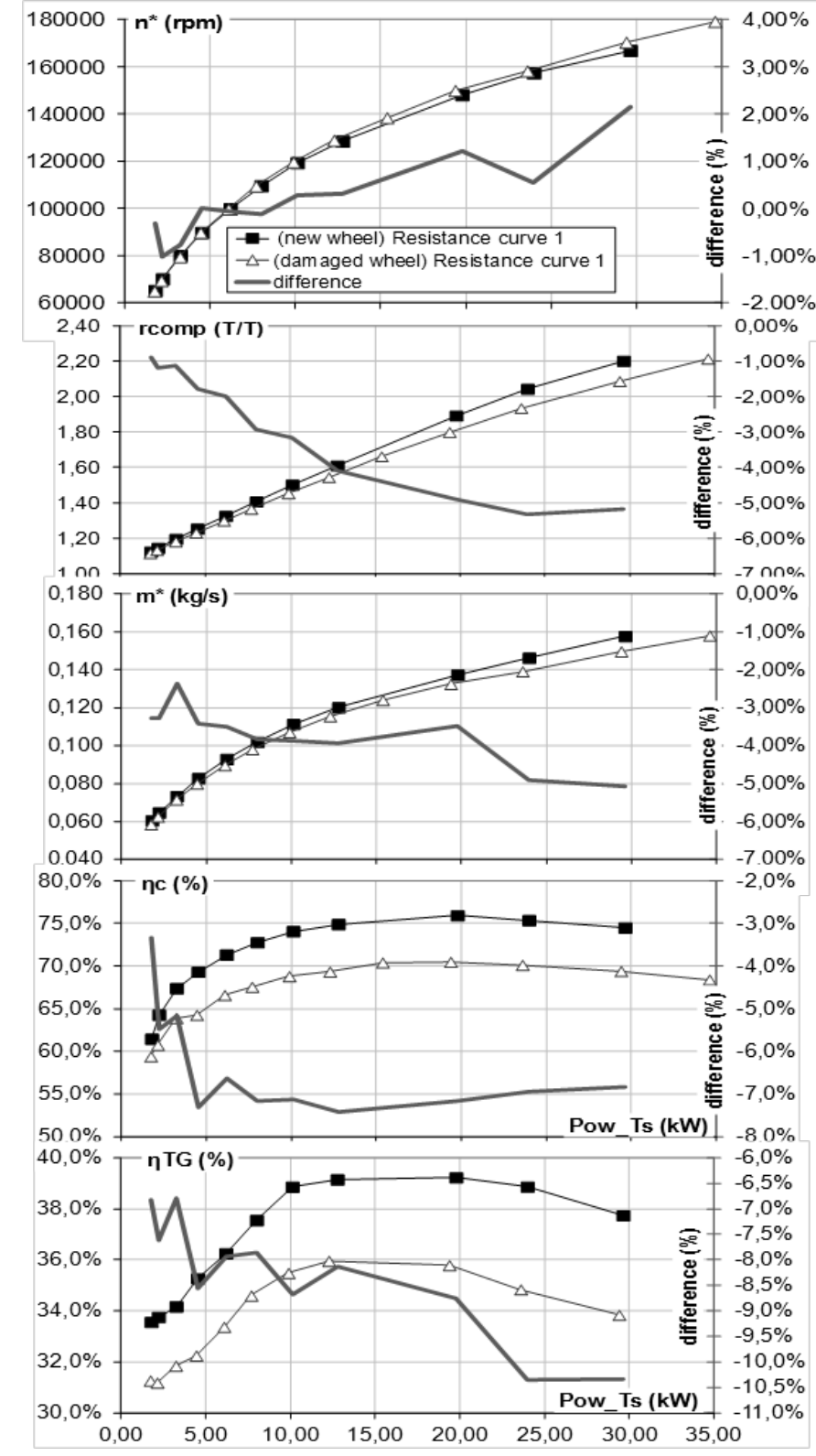

Figure 15. Variables of the damaged wheel test (Resistance curve 1)

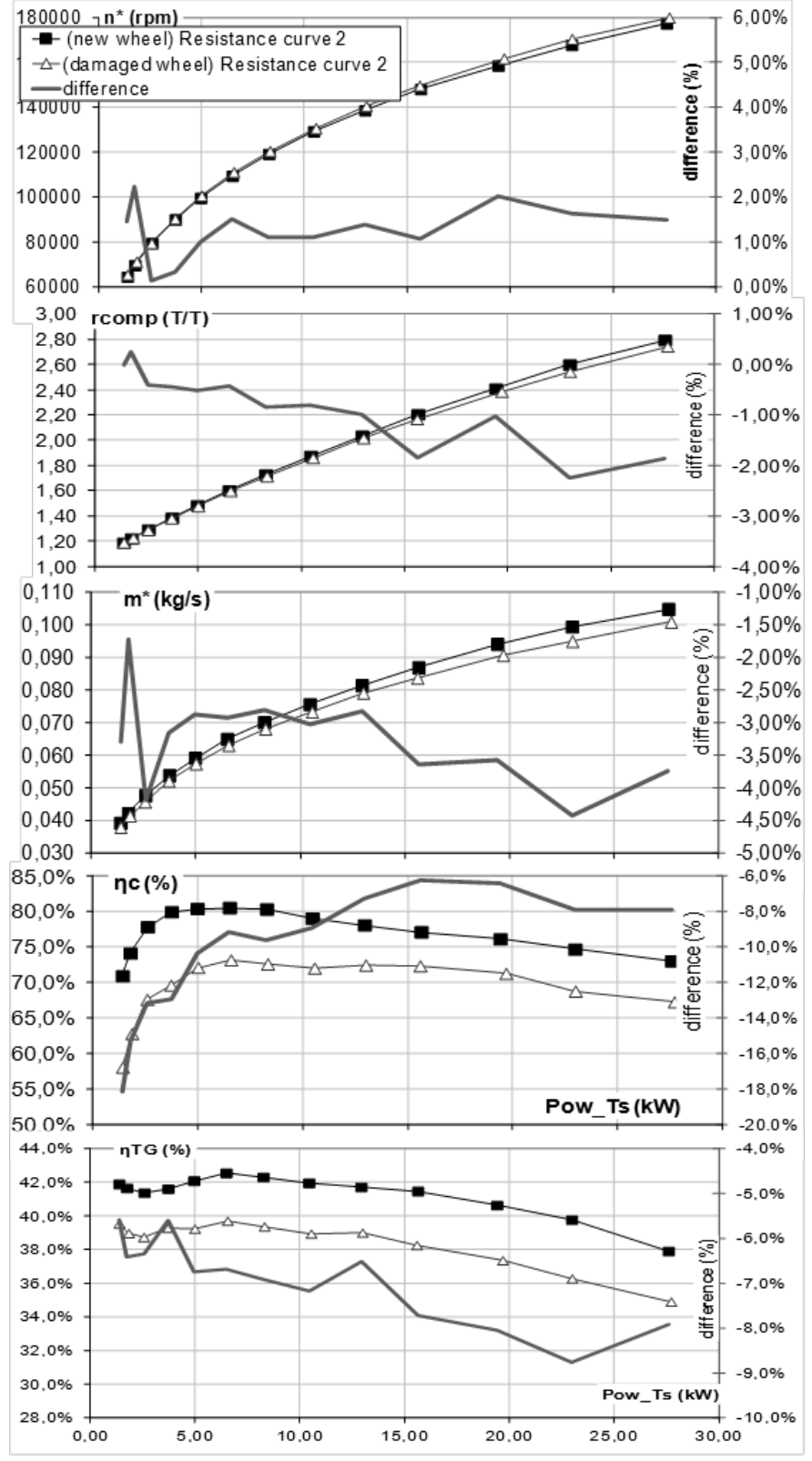

Figure 16. Variables of the damaged wheel test (Resistance curve 2)

\section{CONCLUSIONS}

Studies presented in this paper are aimed to determine which types of defects, produced in turbocharger's components during critical operative conditions, cause its critical failure. That is, that the compressor stops compressing. For this purpose, two different tests were raised: the resistance test, which simulates several cycles of acceleration and deceleration with deficient conditions of oil pressure and the lubrication delay test, which simulates severe delays in the entry of the lubrication during several accelerations of the turbocharger. Some of these critical tests finished with the lost of the turbo performance (the turbocharger does not 
compress). In these cases, an exploded of the damaged turbocharger indicated that major damage had occurred at the tips of the compressor blades, which had been beaten and deformed and the bearings, which had been worn, due to the contact with the shaft.

Due to this, there is an additional experiment to determine the cause of the loss of capacity to the compression in the turbocharger. This experiment consist of comparing the results obtained with a new turbocharger and compare them with the results obtained with the same turbocharger, but changing the new compressor wheel by a damaged wheel in an intermittent lubrication test(with compressor wheel blades bent). These tests were performed at different operating points of the turbo. The result obtained is that the damaged wheel was able to compress, but with a poorer performance, due to aerodynamic problems arising from deformation of its blades. This allowed us to conclude that in this type of experiments, with extreme lubrication conditions, the bearing wear produces ultimately the critical failure of the turbocharger (total lost of boost pressure), due to the increase of the eccentric movement of the shaft and finally, the hitting of the wheel blades with the housing.

Additionally, these experiments have been used to test a nonintrusive novel technique to measure the movement of the turbocharger shaft. This technique has been used in these turbocharger destructive tests with satisfactory results.

The main conclusions of the Lubrication Delay Tests are that accelerations from low rotational speed to $50 \mathrm{krpm}$ and to $100 \mathrm{krpm}$, without lubrication oil in the bearing system, don't cause significant problems in the turbocharger. However, the accelerations to $150 \mathrm{krpm}$ cause critical problems in turbos with semi floating bearings (these problems have been also detected in turbos with floating bearing system only when the lack of lubrication remains over more than $15 \mathrm{sec}$ ). Finally, high acceleration rates to $200 \mathrm{krpm}$, without lubrication, cause the turbocharger destruction in a few seconds.

The main conclusion of the Resistance Tests is that with a low oil inlet pressure, given by an oil column of about $1 \mathrm{~m}$ in height, the turbo can survive during accelerations from low speed to $150 \mathrm{krpm}$.

\section{REFERENCES}

1. Lecointe, B. and Monnier, G., "Downsizing a Gasoline Engine Using Turbocharging with Direct Injection," SAE Technical Paper 2003-01-0542, 2003, doi:10.4271/200301-0542

2. L.Eriksson, "Modeling and Control of Turbocharged SI and CI Engines,” Oil and Gas Science and Technology Rev IFP Volume 62, Number 4, July-August 2007 IFP International Conference. New Trends on Engine Control, Simulation and Modeling, 06 December 2007, doi: 10.2516/ogst:2007042.

Page 9 of 9
3. J. Galindo, J.R. Serrano, C. Guardiola, C. Cervelló, "Surge limit definition in a specific test bench for the characterization of the automotive turbochargers", Experimental Thermal and Fluid Science 30 (2006) 449462, doi: 10.1016/j.expthermflusci.2005.06.002

4. Riccardo Buratti, Alesanddro Carlo, Enrico Lanfranco and Alberto Pisoni, "Di Diesel Engine with Variable Geometry Turbocharger (VGT): A Model Based Boost Pressure Control Strategy”, MECCANICA Volume 32, Number 5 (1997), 409 - 421, doi: 10.1023/A:1004251615880

5. Cantemir, C., "Twin Turbo Strategy Operation," SAE Technical Paper 2001-01-0666, 2001, doi:10.4271/200101-0666

6. Robert A. Keller, “Turbocharger Lubrication System”, United States Patent, Patent number: 4,926,641 May 22, 1990.

7. John W. Evans, "Pressurized Lubrication Assembly For The Center Bearing Of A Turbocharger”, United States Patent, Patent Number : 4,513, 705 Apr. 30, 1985.

8. Martin Neuburger, Karl-Otto Schmidt, Apostolos Tsakiris, "Method And Device Of A Start-Stop Control For An Internal Combustion Engine”, Patent Application Publication, Pub No: US 2011/0174255 A1, Jul. 21, 2011

9. Asmita G. Fulzele, V.G. Arajpure, P.P. Holay, N.M. Patil, Condition monitoring of shaft of single-phase induction motor using optical sensor. Mechanical Systems and Signal Processing 29 (2012) 428 - 435

10. Bernhard Schweizer, Total instability of turbocharger rotors-Physical explanation of the dynamic failure of rotors with full-floating ring bearings. Journal of sound and vibration 328 (2009) 156-190

11. P. Günther, F. Dreier, T. Pfiser, J. Czarske, T. Haupt, W. Hufenbach, Measurement of radial expansion and tumbling motion of a high-speed rotor using an optical sensor system. Mechanical Systems and Signal Processing (2010) doi: 10.1016/j.ymssp.2010.08.005

12. JV Pastor, JR Serrano, V Dolz, MA López, F.Bouffaud. Study of turbocharger shaft motion by means of noninvasive optical techniques. Application to the behaviour analysis in turbocharger lubrication failures. Mechanical Systems and Signal Processing 32 (2012) 292-305. http://dx.doi.org/10.1016/j.ymssp.2012.04.020 